\title{
NOTES
}

\section{A New Leptospiral Serovar in the Icterohaemorrhagiae Serogroup Isolated from an Ox in Zimbabwe}

\author{
SARA B. FERESU, ${ }^{1 *}$ CAROLE A. BOLIN, ${ }^{2}$ AND HANS KORVER ${ }^{3}$ \\ Department of Biological Sciences, University of Zimbabwe, Box MP 167, Mount Pleasant, Harare, \\ Zimbabwe ; Leptospirosis and Mycobacteriosis Research Unit, National Animal Disease Center, \\ Agricultural Research Service, U.S. Department of Agriculture, Ames, Iowa 50010²; and N.H. Swellengrebel \\ Laboratory of Tropical Hygiene, The Royal Tropical Institute, Amsterdam, The Netherlands ${ }^{3}$
}

A strain of Leptospira interrogans that was isolated from an ox slaughtered in Zimbabwe and belonged to serogroup Icterohaemorrhagiae could not be identified when we compared it with 18 reference strains belonging to this serogroup by using cross-agglutinin absorption, monoclonal antibody, and restriction endonuclease DNA analyses. The name zimbabwe is proposed for the new serovar containing this strain; the type strain of this serovar is strain SBF 23.

Leptospira interrogans strains belonging to serogroup Icterohaemorrhagiae were the first members of the genus Leptospira to be isolated (9). Since the initial isolation, the number of serovars belonging to this serogroup has risen to 14 (11), with four other serovars currently being considered (19, 27). Although the majority of these serovars were first isolated from humans, antibodies to serogroup Icterohaemorrhagiae strains have been detected in cattle $(18,24)$, and strains belonging to serogroup Icterohaemorrhagiae have occasionally been associated with clinical disease in naturally infected cattle (5). In Africa, strains belonging to serogroup Icterohaemorrhagiae have been isolated from humans $(8,10,15)$, dogs $(15)$, and rodents $(1-3,14,17)$. Reference strains for serovars mwogolo, ndahambukuje, and ndambari in sero-

TABLE 1. Serovar identification of strain SBF 23 by crossagglutinin absorption

\begin{tabular}{|c|c|c|c|}
\hline Serovar & Antiserum & $\begin{array}{l}\text { Absorbed with } \\
\text { strain: }\end{array}$ & $\begin{array}{l}\text { Reciprocal of homo- } \\
\text { logous titer as a \% } \\
\text { of unabsorbed } \\
\text { serum titer }\end{array}$ \\
\hline \multirow[t]{2}{*}{ birkini } & SBF 23 & Birkin & 25 \\
\hline & Birkin & SBF 23 & 12.5 \\
\hline \multirow[t]{2}{*}{ copenhageni } & SBF 23 & M20 & 50 \\
\hline & M20 & SBF 23 & 50 \\
\hline \multirow[t]{2}{*}{ dakota } & SBF 23 & Grand River & 25 \\
\hline & Grand River & SBF 23 & 50 \\
\hline \multirow[t]{2}{*}{ gem } & SBF 23 & Simon & 50 \\
\hline & Simon & SBF 23 & 12.5 \\
\hline \multirow[t]{2}{*}{ lai } & SBF 23 & Lai & 6.2 \\
\hline & Lai & SBF 23 & 25 \\
\hline \multirow[t]{2}{*}{ mankarso } & SBF 23 & Mankarso & 50 \\
\hline & Mankarso & SBF 23 & 50 \\
\hline \multirow[t]{2}{*}{ mwogolo } & SBF 23 & Mwogolo & 25 \\
\hline & Mwogolo & SBF 23 & 12.5 \\
\hline \multirow[t]{2}{*}{ ndahambukuje } & SBF 23 & Ndahambukuje & 25 \\
\hline & Ndahambukuje & SBF 23 & 25 \\
\hline
\end{tabular}

* Corresponding author. group Icterohaemorrhagiae were first isolated from humans in Zaire (25).

The current classification of the bacteria that belong to the genus Leptospira is based on serological criteria. The microscopic agglutination test and the cross-agglutinin absorption test are the standard reference procedures used for serological classification of leptospires (4). When these methods are used, two strains are considered to belong to different serovars if after cross-absorption with adequate amounts of heterologous antigen, $10 \%$ or more of the homologous titer regularly remains in at least one of the two antisera in repeated tests. The methodology cannot be standardized and, therefore, sometimes is not reproducible. It may also fail to distinguish between genetically different but antigenically similar strains.
TABLE 2. Reciprocals of agglutination titers of MAbs with serogroup Icterohaemorrhagiae reference serovars and Zimbabwe strain SBF 23

\begin{tabular}{|c|c|c|c|c|}
\hline \multirow{2}{*}{ Subgroup } & \multirow{2}{*}{ Strain or serovar } & \multicolumn{3}{|c|}{ Reciprocal of agglutination titer with: } \\
\hline & & MAb F70C7 & MAb F20C4 & MAb F82C2 \\
\hline \multirow[t]{4}{*}{ I } & bogvere & 40,960 & 2,560 & $-a$ \\
\hline & copenhageni & 81,920 & 81,920 & - \\
\hline & icterohaemorrhagiae & 40,960 & 20,480 & - \\
\hline & ndahambukuje & 81,920 & 10,240 & - \\
\hline \multirow[t]{5}{*}{ II } & dakota & 81,920 & 40,960 & 20,480 \\
\hline & hongchon & 40,960 & 10,240 & 10,240 \\
\hline & mankarso & 81,920 & 20,480 & 81,920 \\
\hline & naam & 81,920 & 10,240 & 81,920 \\
\hline & yeonchon & 81,920 & 2,560 & 10,240 \\
\hline \multirow[t]{5}{*}{ III } & honghe & 81,920 & - & - \\
\hline & nanxi & 40,960 & - & - \\
\hline & ndambari & 20,480 & - & - \\
\hline & smithi & 81,920 & - & - \\
\hline & tonkini & 81,920 & - & - \\
\hline \multirow[t]{5}{*}{ IV } & birkini & 81,920 & - & 2,560 \\
\hline & gem & 81,920 & - & 1,280 \\
\hline & lai & 40,960 & - & 40,960 \\
\hline & mwogolo & 20,480 & - & 10,240 \\
\hline & $S B F 23$ & 20,480 & - & 20,480 \\
\hline
\end{tabular}

$a-,<20$. 

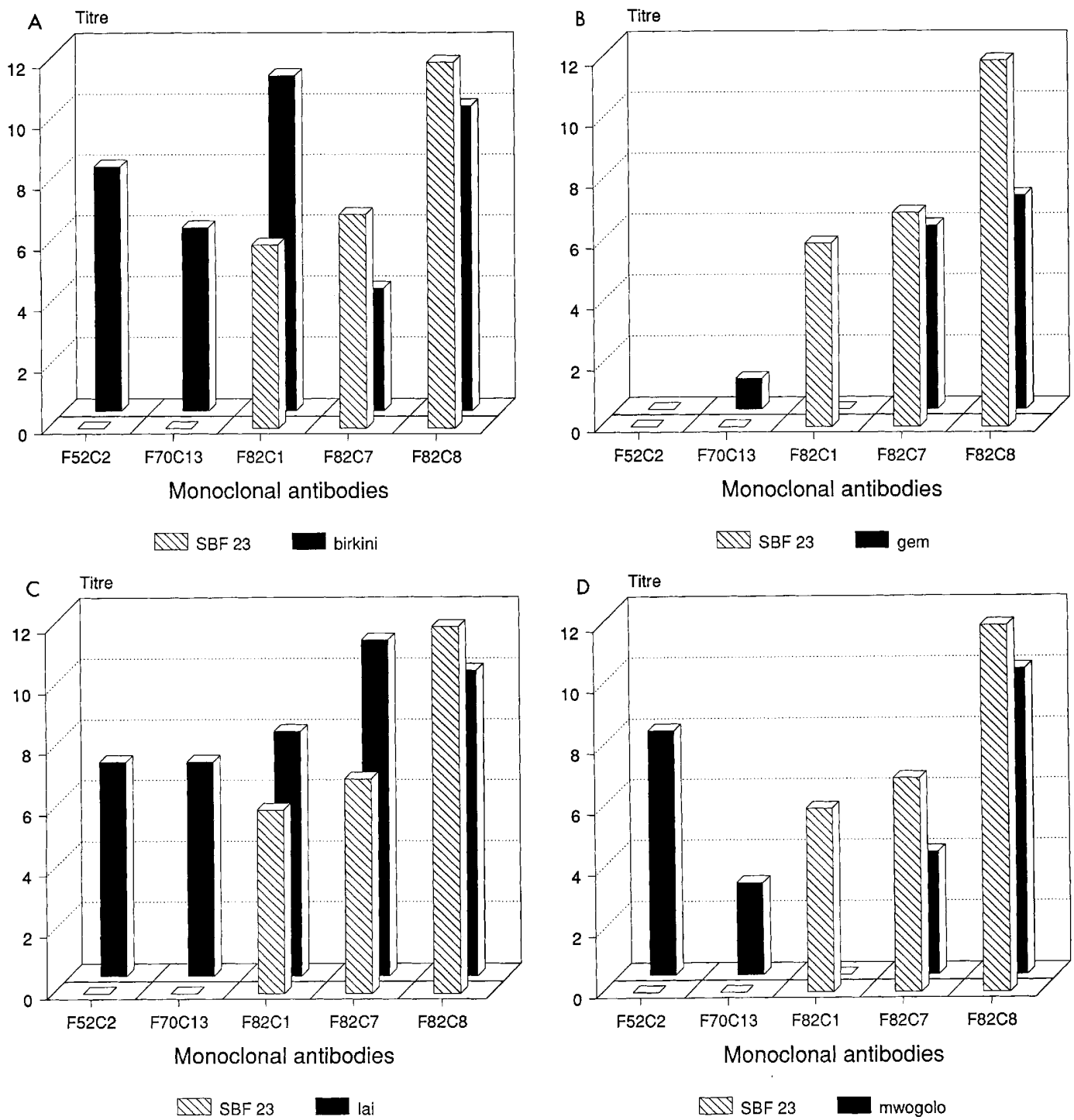

FIG. 1. Agglutination profiles (microscopic agglutinin test titers) of MAbs with serogroup Icterohaemorrhagiae serovars birkini, gem, lai, and mwogolo and strain SBF 23. The vertical axis indicates serial twofold dilutions, starting from 1:20 (1), 1:40 (2), etc. (0 = <1:20). (A) Cross-hatched bars, strain SBF 23; solid bars, serovar birkini. (B) Cross-hatched bars, strain SBF 23; solid bars, serovar gem. (C) Cross-hatched bars, strain SBF 23; solid bars, serovar lai. (D) Cross-hatched bars, strain SBF 23; solid bars, serovar mwogolo.

Mouse monoclonal antibodies (MAbs) have been used as an additional serological method to identify organisms belonging to the genus Leptospira $(12,13,21)$. The MAb technique is accurate but still depends on the detection of surface antigens and on careful selection of antibodies that discriminate between serovars.

Restriction endonuclease analysis (REA) of leptospiral DNA was first proposed as an alternative method for classifying leptospires by Marshall et al. (16). After improvements in the DNA extraction procedure and resolution of the restricted DNA fragments in agarose gels $(22,23)$, REA has proven to be a more sensitive and discriminating method than serotyping. However, the banding pattern obtained with REA may be complicated and/or difficult to read. REA may also fail to find differences between antigenically different strains. For example, serovars wolff and roumanica, serovars istrica and nyanza, and serovars polonica and sejroe in serogroup Sejroe (23) and serovars tarassovi, guidae, tunis, and moldaviae in serogroup Tarassovi have similar digestion patterns and are not easily differentiated by REA alone (28).

On the basis of DNA relatedness results, Yasuda et al. (26) have proposed that $L$. interrogans should be divided into the following five species: Leptospira borgpetersenii, L. interrogans, Leptospira noguchii, Leptospira santarosai, and Leptospira weilii. However, although many leptospirosis laboratories have adopted this classification and are trying to develop and test it, the new classification has not been adopted yet by the Subcommittee on the Taxonomy of Leptospira.

Pending the adoption of a completely new classification system, Terpstra (20) has proposed that serological methods complemented by REA patterns produced by using one or more restriction enzymes should be used for the allocation of new strains to serovars.

The isolation and serogrouping of a strain belonging to 


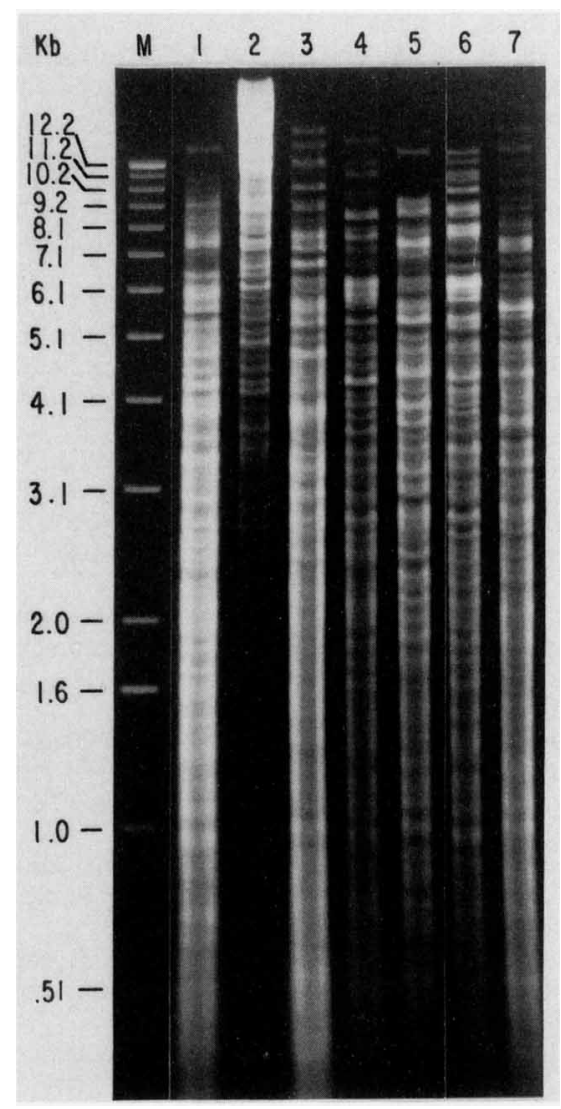

FIG. 2. Electrophoretic patterns of chromosomal DNAs from reference strains of serogroup Icterohaemorrhagiae and strain SBF 23 digested with $E c o$ RI. The reference strains were strains belonging to serovars mankarso (lane 1), ndahambukuje (lane 2), dakota (lane 3), lai (lane 4), mwogolo (lane 5), and birkini (lane 6). Lane 7 contained strain SBF 23 . Lane $M$ contains fragment size markers (sizes are given in kilobase pairs).

serogroup Icterohaemorrhagiae in Zimbabwe have been described previously (6). In this paper we describe the identification of this strain to serovar level, which was accomplished by using the cross-agglutinin absorption test, $\mathrm{MAb}$ analysis, and REA.

Antisera from 18 reference strains belonging to serogroup Icterohaemorrhagiae and strain SBF 23 for use in the crossagglutinin absorption tests were produced in paired rabbits and were pooled before use as previously described (7).

Strain SBF 23 was tested against the serogroup Icterohaemorrhagiae reference antisera, and the serogroup Icterohaemorrhagiae reference strains were tested against antiserum to strain SBF 23 by using the microscopic agglutination test. Only those reference strains which had a reciprocal titer of at least $1: 1,600$ with strain SBF 23 were used for the cross-agglutinin absorption test. Strain SBF 23 had a reciprocal titer of less than 1:1,600 with antisera raised against reference strains belonging to serovars bogvere, icterohaemorrhagiae, naam, ndambari, smithi, and tonkini. Apparently, strain SBF 23 shares little similarity with members of these serovars, and therefore, they were excluded from the cross-agglutinin absorption tests with strain SBF 23.

High-level reactions ( $>50 \%$ of the reciprocal titer of the homologous strain) were observed with strains belonging to serovars birkini, copenhageni, dakota, gem, lai, mankarso,

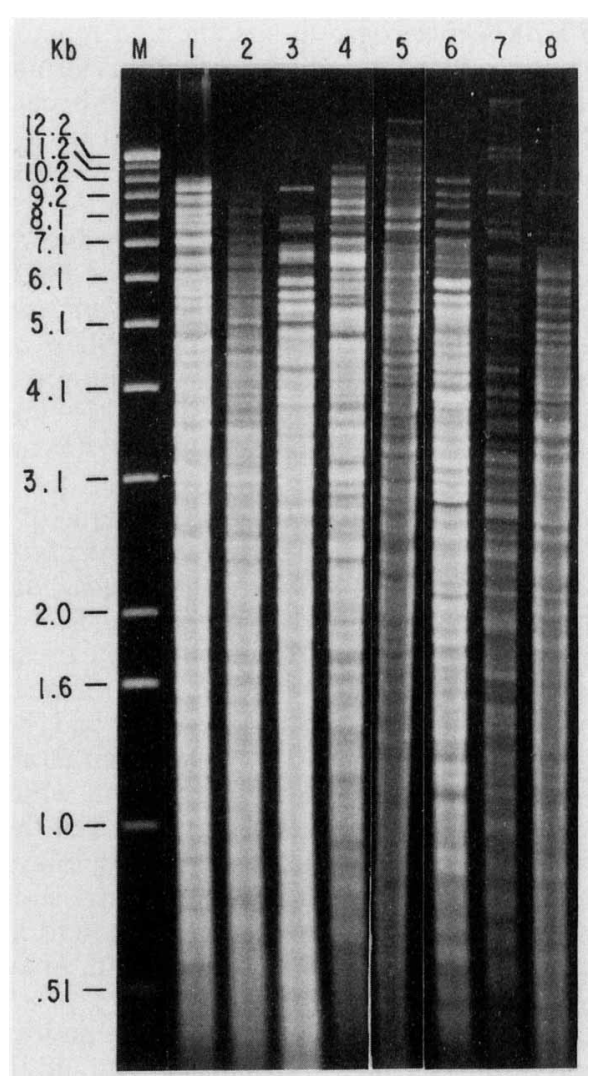

FIG. 3. Electrophoretic patterns of chromosomal DNAs from reference strains of serogroup Icterohaemorrhagiae and strain SBF 23 digested with $H$ hal. The reference strains were strains belonging to serovars birkini (lane 1), copenhageni (lane 2), dakota (lane 3), lai (lane 4), gem (lane 5), mwogolo (lane 6), and ndahambukuje (lane 7). Lane 8 contained strain SBF 23. Lane M contains fragment size markers (sizes are given in kilobase pairs).

mwogolo, ndahambukuje, hongchon, honghe, nanxi, and yeonchon. These reference strains were included in the cross-agglutinin absorption tests. The cross-agglutinin absorption tests were performed as described previously (7), except that the results were checked by using both the Bratislava and Amsterdam techniques (4).

Only one-side absorption tests were performed with antisera from strains belonging to the recently discovered but not yet officially recognized serovars hongchon, honghe, nanxi, and yeonchon. More than $25 \%$ of the antibodies remained in their antisera after absorption with strain SBF 23 , indicating that the Zimbabwe isolate did not belong to these serovars.

The results of the cross-agglutinin absorption tests with strain SBF 23 and the reference strains are shown in Table 1. These results indicate that although strain SBF 23 appears to be closely related to serovar birkini, gem, lai, and mwogolo strains, it is antigenically different from members of all of the previously described serovars of serogroup Icterohaemorrhagiae because more than $10 \%$ of the antibodies remained in at least one of the two antisera. Therefore, on the basis of the current definition of a serovar, strain SBF 23 represents a new serovar in serogroup Icterohaemorrhagiae.

MAbs were produced as previously described $(12,21)$. Three MAbs (MAbs F70C7, F20C4, and F82C2) were used to divide the serogroup Icterohaemorrhagiae reference strains and Zimbabwe isolate SBF 23 into subgroups (Table 
2). MAb F70C7 is serogroup specific and reacted at a high level with strain SBF 23, indicating that this strain belongs to serogroup Icterohaemorrhagiae. Two other broadly reactive MAbs (MAbs F20C4 and F82C2) enabled us to divide the serogroup into four subgroups. Strain SBF 23 showed the same pattern as the members of subgroup IV.

The agglutination profiles obtained with five other MAbs (MAbs F52C2, F70C13, F82C1, F82C7, and F82C8) (Fig. 1) separated strain SBF 23 from serovars birkini, gem, lai, and mwogolo. Therefore, the results of the MAb analysis are consistent with those of the cross-agglutinin absorption tests, showing that although strain SBF 23 is closely related to serovars birkini, gem, lai, and mwogolo, it is antigenically distinct from these serovars.

The restriction endonuclease DNA patterns of strain SBF 23 and serogroup Icterohaemorrhagiae serovar birkini, copenhageni, dakota, gem, lai, mankarso, mwogolo, and ndahambukuje reference strains were compared. The selection of these serovars was based on the results of the cross-agglutinin absorption tests. Bacterial DNA extraction, restriction endonuclease digestion, gel electrophoresis, and photography were carried out as described by Thiermann et al. (22).

Strain SBF 23 produced a unique pattern which could be differentiated easily from the patterns of all of the reference strains when the DNAs were digested with enzymes EcoRI (Fig. 2) and HhaI (Fig. 3). This finding supported the serological data and indicated that in addition to representing a new serovar, strain SBF 23 also represents a new genotype in serogroup Icterohaemorrhagiae.

The name zimbabwe is proposed for the new serovar; the type strain of this serovar is strain SBF 23, and this strain is available from the collections of Leptospirosis Reference Laboratories.

The significance of this new serovar as a pathogen of cattle, other domestic animals, and humans is unknown since no clinical syndrome was associated with the isolation of strain SBF 23.

We thank Annette Handsaker and John Foley for technical assistance.

Isolation work was financed by grants from the University of Zimbabwe Research Board and the International Foundation for Science. The isolates were characterized at The National Animal Disease Center, Ames, Iowa, and The Royal Tropical Institute, Amsterdam, The Netherlands. S.B.F. was sponsored by Forgarty USA Public Service International Research Fellowship 1 F05 TW4154-01.

\section{REFERENCES}

1. Bakoss, P., and A. Chadli. 1965. Identification des souches de Leptospira icterohaemorrhagiae isoleés ă Tunis. Arch. Inst. Pasteur Tunis 42:59-66.

2. Ball, M. G. 1966. Animal hosts of leptospires in Kenya and Uganda. Am. J. Trop. Med. Hyg. 15:523-530.

3. Baylet, R., and J. Van Riel. 1971. Cricetomys gambianus, nouvel hôte de conservation de leptospires. Med. Afr. Noire 18:803-805.

4. Dikken, H., and E. Kmety. 1978. Serological typing methods of leptospires. Methods Microbiol. 11:259-307.

5. Ellis, W. A., J. J. O'Brien, S. Neill, J. Hanna, and D. G. Bryson. 1977. The isolation of a strain of Leptospira serogroup Icterohaemorrhagiae from an aborted bovine foetus. Br. Vet. J. 133:108-109.

6. Feresu, S. B. 1992. Isolation of Leptospira interrogans from kidneys of Zimbabwe beef cattle. Vet. Rec. 130:446-448.

7. Feresu, S. B., and C. A. Bolin. 1991. Characterization of Leptospira interrogans isolated from cattle in Zimbabwe, p. 215-224. In Y. Koyabashi (ed.), Leptospirosis. Proceedings of the Leptospirosis Research Conference 1990. University of
Tokyo Press, Tokyo.

8. Hogerzeil, H. V., A. de Geus, W. J. Terpstra, H. Korver, and G. S. Ligthart. 1986. Leptospirosis in rural Ghana. II. Current leptospirosis. Trop. Geogr. Med. 38:408-414.

9. Inada, R., and Y. Ido. 1915. The causative agent of Weil's disease: a summarized report of the discovery of a new species of Spirochaeta. Tokyo Ijishinshi 1908:351-360. (In Japanese.)

10. Joyce-Clarke, N., and M. J. Michaels. 1968. Leptospirosis in Cape Town. S. Afr. Med. J. 42:57-58.

11. Kmety, E., and H. Dikken. 1988. Revised list of Leptospira serovars. International Committee on Systematic Bacteriology of the International Union of Microbiological Societies Subcommittee on the Taxonomy of Leptospira. University Press, Groningen, The Netherlands.

12. Korver, H., W. A. Ellis, M. J. Kim, and W. J. Terpstra. 1991. Antigenic and genetic analysis of Korean Leptospira isolates, p. 235-270. In Y. Koyabashi (ed.), Leptospirosis. Proceedings of the Leptospirosis Research Conference 1990. University of Tokyo Press, Tokyo.

13. Koyabashi, Y., T. Tamai, T. Oyama, H. Hasegawa, E. Sada, T. Kusaba, and M. Hamaji. 1984. Characterization of monoclonal antibodies against etiological agents of Weil's disease. Microbiol. Immunol. 28:359-370.

14. Kranendonk, O., J. W. Wolff, H. J. Bohlander, J. M. D. Roberts, A. de Geus, and R. Njenga. 1968. Leptospirosis in Kenya. World Health Organization/Zoonosis Technical Report 69:1-5.

15. Mailloux, M., and B. Kolochine-Erbert. 1961. Les leptospiroses dans les anciens territoires de l'Union Francaise. Z. Tropenmed. Parasitol. 12:307-325.

16. Marshall, R. B., B. E. Wilton, and A. J. Robinson. 1981. Identification of Leptospira serovars by restriction-endonuclease analysis. J. Med. Microbiol. 14:163-166.

17. McGuire, C. D., and D. M. Myers. 1957. Leptospirosis in Egypt. Am. J. Trop. Med. Hyg. 6:532-539.

18. Michna, S. W. 1967. Animal leptospirosis in the British Isles: a serological survey. Vet. Rec. 80:394-401.

19. Oh, H. B., W. H. Chang, M. K. Cho, W. K. Seong, and K. S. Park. 1991. Identification of new serovars yeonchon and hongchon belonging to Leptospira interrogans Icterohaemorrhagiae serogroup. J. Korean Soc. Microbiol. 26:253-262.

20. Terpstra, W. J. 1991. Typing Leptospira from the perspective of a reference laboratory. Acta Leiden 60:79-87.

21. Terpstra, W. J., H. Korver, J. V. Leeuwen, P. R. Klatser, and A. H. J. Kolk. 1985. The classification of Sejroe group serovars of Leptospira interrogans with monoclonal antibodies. Zentralbl. Bakteriol. Parasitenkd. Infektionskr. Hyg. Abt. 1 Orig. Reihe A 259:498-506.

22. Thiermann, A. B., A. L. Handsaker, J. W. Foley, F. H. White, and B. F. Kingscote. 1986. Reclassification of North American leptospiral isolates belonging to serogroups Mini and Sejroe by restriction endonuclease analysis. Am. J. Vet. Res. 47:61-66.

23. Thiermann, A. B., A. L. Handsaker, S. L. Moseley, and B. Kingscote. 1985. New method for classification of leptospiral isolates belonging to serogroup Pomona by restriction endonuclease analysis: serovar kennewicki. J. Clin. Microbiol. 21:585587.

24. Twigg, G. I., D. M. Hughes, and A. McDiarmid. 1972. Leptospiral antibodies in dairy cattle: some ecological considerations. Vet. Rec. 90:598-602.

25. Van Riel, J. 1946. Le foyer centro-africain de leptospirose. Ann. Soc. Belge Med. Trop. 26:197-313.

26. Yasuda, P. H., A. G. Steigerwalt, K. R. Sulzer, A. F. Kaufmann, F. Rogers, and D. J. Brenner. 1987. Deoxyribonucleic acid relatedness between serogroups and serovars in the family Leptospiraceae with proposals for seven new Leptospira species. Int. J. Syst. Bacteriol. 37:407-415.

27. Zhang, F. Z. 1989. Discussion on the nomenclature of the new leptospiral serovars found in China. Chin. J. Epidemiol. 10:239 244. (In Chinese.)

28. Zuerner, R. L., and C. A. Bolin. 1990. Nucleic acid probe characterizes Leptospira interrogans serovars by restriction fragment length polymorphisms. Vet. Microbiol. 24:355-366. 